\title{
IZ LIJEČNIČKE BIOGRAFIJE PRIM. DR. LJUBICE BOSNER
}

\section{FROM PHYSICIAN'S BIOGRAPHY OF PRIMARIUS LJUBICA BOSNER}

\author{
Dubravko Habek*, Marko Mikulec*
}

\begin{abstract}
SAŽETAK
Prethodno su objavljeni i poznati podatci o Riječanki prim. dr. Ljubici Bosner, o njezinu djelovanju u ogulinskoj, bjelovarskoj, petrinjskoj i riječkoj bolnici tijekom njezina zavidna kirurškoga i ginekološko-porodničkog staža. Novi i sada dostupni arhivaliji osobnih i profesionalnih personalija upotpunjuju nepotpune i neznane biografske podatke. Nakon pripravničkoga staža radila je u javnoj županijskoj bolnici u Velikoj Gorici kao sekundarna liječnica na poznatom ortopedskom odjelu te bolnice. Okolnosti odlaska u ogulinsku bolnicu s polaganjem zakletve vladajućem kralju Petru II. na vjernost, potom njezina profesionalna aktiunost kirurginje u novootvorenoj Zakladnoj bolnici na Rebru u Zagrebu uz povremene odlaske na mjesto ravnateljice bolnice i kirurginja u Petrinji i Varaždinu, a u poraću na nova radna mjesta u Oblasnom NO-u Istra, posebno su socijalno-povijesno zanimljive. Pronađene su preporuke njezinih šefova za priznavanjem zvanja specijalista kirurga koji naglašavaju njezinu spretnost, kliničku prosudbu i obavljanje teških operacijskih zahvata, posebice za vrijeme rata. U svome je životu $i$ liječničkoj karijeri prolazila razdoblja velike krize između dvaju svjetskih ratova (za vrijeme Kraljevine Srba, Hrvata i Slovenaca), potom Drugoga sujetskog rata (za vrijeme Nezavisne Države Hrvatske) te poraća (za vrijeme Republike Jugoslavije), u kojima je djelovala kao kirurginja. Navedene podatke u biografiji prim. dr. Ljubice Bosner upotpunjuju do sada neznane i neobjavljene fotografije iz njezina osobnog i profesionalnog, kirurškog života.
\end{abstract}

Ključne riječi: povijest medicine, povijest kirurgije, Ljubica Bosner, Hrvatska

* Hrvatsko katoličko sveučilište u Zagrebu / Klinika za ginekologiju i porodništvo Kliničke bolnice Sveti Duh u Zagrebu, Zagreb, Hrvatska

Adresa za dopisivanje: Dubravko Habek, Hrvatsko katoličko sveučilište u Zagrebu, Ilica 242, 10000 Zagreb / Klinika za ginekologiju i porodništvo Kliničke bolnice Sveti Duh u Zagrebu, Sveti Duh 64, 10000 Zagreb. ORCID ID: https://orcid.org/0000-0003-1304-9279.E-pošta: dhabek@unicath.hr. 


\section{UvoD}

Uvidom u Zbirku personalnih spisa službenika Zemaljske vlade, Pokrajinske uprave, oblasnih uprava, Savske banovine, Banovine Hrvatske i ministarstava Nezavisne Države Hrvatske (NDH), koja je sada dostupna istraživačima, pronađeni su brojni dokumenti i fotografije koji upotpunjuju profesionalnu biografiju prim. dr. Ljubice Bosner. Prema krsnome listu dr. Ljubica Bosner rođena je 2. veljače, a krštena 26. travnja 1902. kao Ljubica Amalia Maria u župi Uznesenja Blažene Djevice Marije u Rijeci. ${ }^{1}$

Poput ostalih liječnika toga vremena, i u životu i u karijeri prolazila je kroz razdoblja velike krize između dvaju svjetskih ratova (za vrijeme Kraljevine), potom Drugoga svjetskoga rata (za vrijeme Nezavisne Države Hrvatske) te poraća (za vrijeme Republike Jugoslavije), u kojima je djelovala kao kirurginja. Prethodno objavljeni rad o prim. dr. Ljubici Bosner temeljio se na tada poznatim i dostupnim arhivskim vrelima koji su navedeni u literaturi o njezinu djelovanju u ogulinskoj, bjelovarskoj, petrinjskoj i riječkoj bolnici tijekom njezina zavidna kirurškoga i ginekološko-porodničkog staža. ${ }^{2} \mathrm{O}$ njezinu namještenju i djelovanju u Zakladnoj bolnici u Zagrebu originalni arhivalij nije bilo dostupan donedavno pa dobiveni podatci i dokumenti upotpunjuju njezinu biografiju i spoznaje o zbivanjima u hrvatskome zdravstvu, posebice tijekom Drugoga svjetskoga rata.

\section{Služba DR. LJubice Bosner}

Prema Službeničkom listu Kraljevine Srba, Hrvata i Slovenaca, nakon završenog studija medicine na zagrebačkom Medicinskom fakultetu, dr. Ljubica Bosner obavila je jednogodišnji pripravnički staž od 8. srpnja ig29. do I9. srpnja 1930. na klinici u Zagrebu, a potom je postavljena na mjesto sekundarnoga liječnika I. kategorije, IX. grupe, I. stupnja, Opće javne županijske bolnice u Velikoj Gorici, gdje je radila na Ortopedskom odjelu od 24 . srpnja 1930. do 20. ožujka 193.., ${ }^{3,4}$ iako su postojali podatci da je u Velikoj

1 Hrvatski državni arhiv Zagreb, Zbirka 890. Zbirka personalnih spisa državnih službenika Zemaljske vlade, Pokrajinske uprave, oblasnih uprava, Savske banovine, Banovine Hrvatske i ministarstava Nezavisne Države Hrvatske.

2 Habek, Dubravko (2013), Prim. dr. Ljubica Bosner, kirurginja, porodničarka i ginekologinja, Acta Med Hist Adriat, 11(2), 237.

3 Hrvatski državni arhiv Zagreb, Zbirka 890. Zbirka personalnih spisa državnih službenika Zemaljske vlade, Pokrajinske uprave, oblasnih uprava, Savske banovine, Banovine Hrvatske i ministarstava Nezavisne Države Hrvatske.

4 Hrvatski državni arhiv Zagreb, Fond 226. Ministarstvo zdravstva i udružbe Nezavisne Države Hrvatske (MZU NDH), Odjel za zdravstvo (OzZ). 


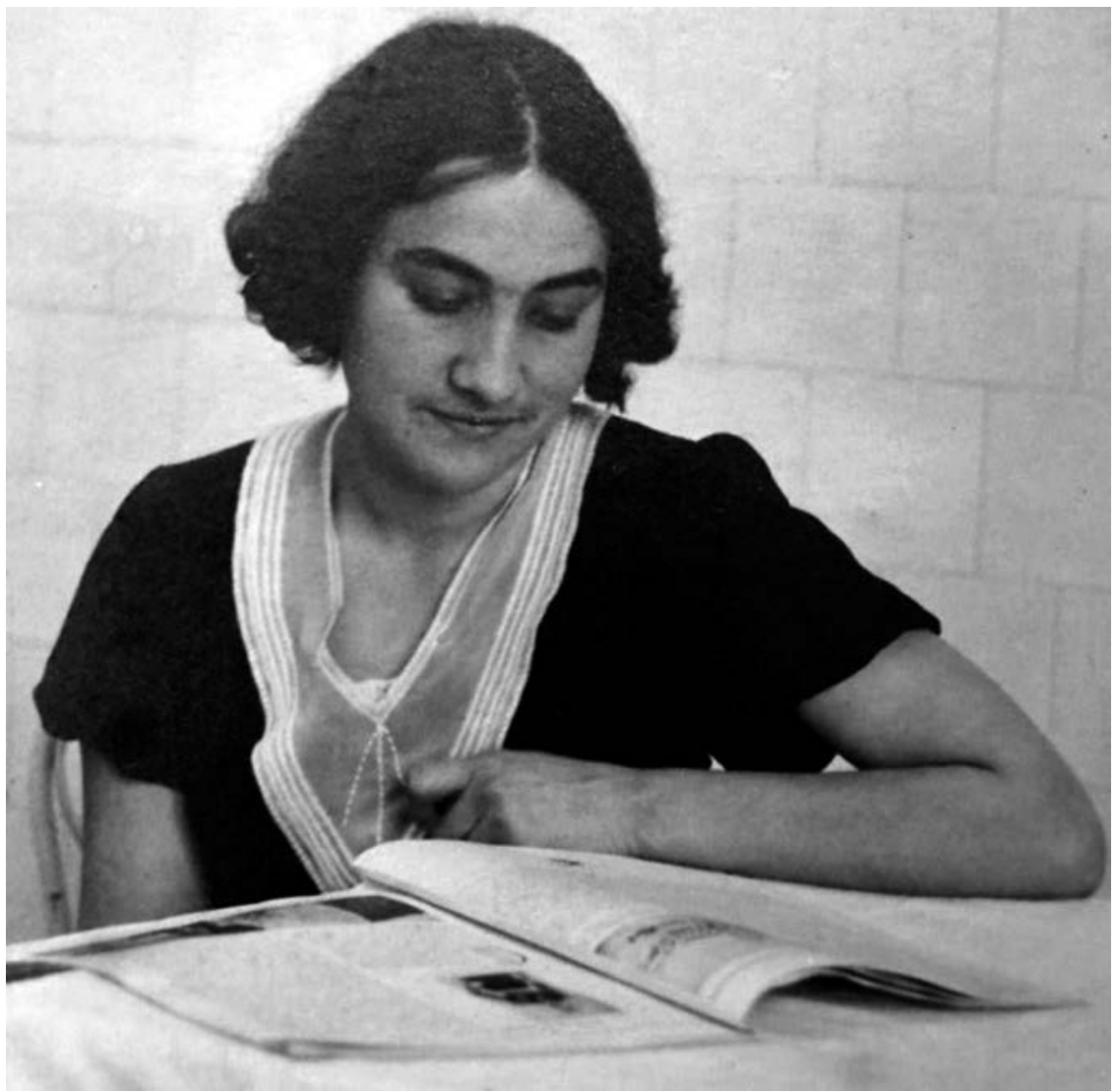

Slika ı. Dr. Ljubica Bosner 1930. kao sekundarna liječnica Ortopedskoga odjela bolnice u Velikoj Gorici.

Gorici radila kao liječnica opće prakse., ${ }^{5,6}$ Bolnica u Velikoj Gorici je I93I. nosila naslov Bolnica uzadruženih zdravstvenih općina Savske banovine, a bila je poznata posebice po Ortopedskom odjelu i filijali Pasteurova zavoda od I92r. do I923. godine. Ortopedski odjel u velikogoričkoj bolnici vodio je poznati ortoped prim. dr. Mato Šarčević (I890. - 1957.), ${ }^{7}$ koji je bio prvi šef dr. Bosner iz operativne struke gdje je i počela stjecati znanja i vještine iz operacijske i konzervativne ortopedije. Godine 1933. preustrojem zdravstvenih ustanova i zatvaranjem bolnice u Velikoj Gorici, odjel se sa 60 kreveta seli u bolnicu u Osijek s istim predstojnikom. ${ }^{8}$

\footnotetext{
Habek, D. (2013), 237.

Škarpa, Antun. Prim. dr. Ljubica Bosner. Pismo. Privatno vlasništvo.

Državni arhiv Zagreb, Fond 1282. Opća javna županijska bolnica Velika Gorica.

8 Habek, Dubravko (2009), Prve liječnice u Bjelovaru: porodničarka i kirurginje, Liječ Vjesn $131,155$.
} 
Nakon službe u Velikoj Gorici, dr. Bosner dobiva namještenje sekundarne liječnice u Banovinskoj bolnici u Ogulinu 1931., o čemu iscrpno govori njezina profesionalna biografija. ${ }^{9}$ Pred upravnikom bolnice prim. dr. Josipom Vodehnalom ro. listopada 1934. položila je i potpisala zakletvu vladajućem kralju Petru II. i otadžbini na srpskom jeziku:

Ja, Ljubica Bosner zaklinjem se Jedinim i Svemogućim Bogom, da ću vladajućem Kralju Petru II. i Otadžbini biti veran, da ću svoju dužnost po zakonima $i$ zakonitim naredbama vršiti savesno, marljivo i nepristrano, imajući na umu jedino opšte javne interese izbegavajući sve ono, što bi moglo biti na štetu poverene mi službe, da ću čuvati svoj ugled $i$ ugled svojih starešina, da ću čuvati službene tajne i uopšte izbegavati sve ono, što bi moglo nauditi poverenju u moj položaj. Tako mi Bog pomogao. ${ }^{10}$

Uz posao u ogulinskoj bolnici, mogla je i putovati po Europi pa joj je u kolovozu 1933. od tadašnjih državnih institucija odobreno putovanje u Francusku preko Austrije i Švicarske. ${ }^{11,12}$

Iz Ogulinske je bolnice 1935. premještena u bolnicu Bjelovar kao sekundarna liječnica VIII. položajne grupe na Kirurško-ginekološkom odjelu pod primarijatom dr. Nikole Karlića, da bi 30. travnja 1938. Odlukom bana Savske banovine gospodina dr. Ružića bila promaknuta u zvanje asistentice VII. položajne grupe s povećanjem plaće. Budući da se rad liječnika toga vremena ocjenjivao, njezin je profesionalni rad Komisija za ocjenu rada iz Zagrebu ocijenila od 1932. do 1938. ocjenom vrlo dobar. ${ }^{13}$ Nakon odlaska prim. dr. Nikole Karlića u mirovinu, dr. Bosner radi s prim. dr. Josipom Jagodićem sve do odlaska iz Bjelovara. Njezin rad u Državnoj bolnici u Bjelovaru iscrpno je opisan i potkrijepljen primjerima iz sačuvanih Operacijskih protokola bjelovarske bolnice za vrijeme Drugoga svjetskoga rata. ${ }^{14,15,16}$

9 Habek, D. (2013), 237.

10 Hrvatski državni arhiv Zagreb, Zbirka 890. Zbirka personalnih spisa državnih službenika Zemaljske vlade, Pokrajinske uprave, oblasnih uprava, Savske banovine, Banovine Hrvatske i ministarstava Nezavisne Države Hrvatske.

11 Ibid.

12 Hrvatski državni arhiv Zagreb, Fond 226. Ministarstvo zdravstva i udružbe Nezavisne Države Hrvatske (MZU NDH), Odjel za zdravstvo (OzZ).

13 Hrvatski državni arhiv Zagreb, Zbirka 890. Zbirka personalnih spisa državnih službenika Zemaljske vlade, Pokrajinske uprave, oblasnih uprava, Savske banovine, Banovine Hrvatske i ministarstava Nezavisne Države Hrvatske.

14 Habek, Dubravko (2013), 237.

15 Habek, Dubravko (2009), Kirurška služba u Bjelovaru tijekom II. svjetskog rata, Liječ Vjesn, 131, 93.

16 Habek, Dubravko (2009), Prve liječnice u Bjelovaru: porodničarka i kirurginje, Liječ Vjesn, 131, 155. 


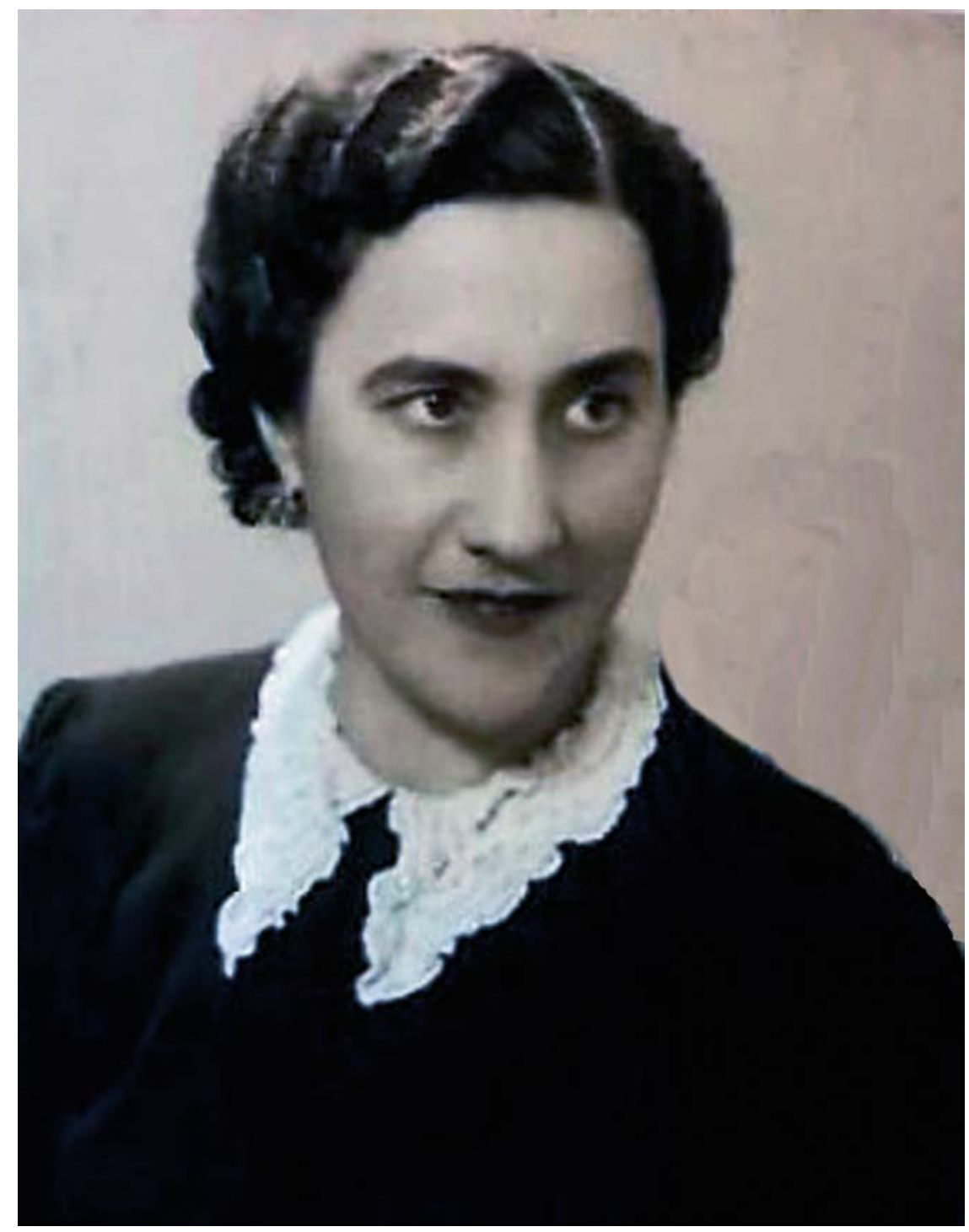

Slika 2. Dr. Ljubica Bosner 1936. za vrijeme službovanja u bjelovarskoj bolnici.

Prim. dr. Josip Jagodić, predstojnik Kirurškoga odjela Državne bolnice u Bjelovaru, svojoj je suradnici i asistentici Državne bolnice u Bjelovaru dr. Ljubici Bosner 25. srpnja I942. izdao potvrdu: radila je kirurške i ginekološke operacije i najteže posve samostalno kao i sve vrsti patoloških poroda. Sve pretrage kirurške, ginekološke i porođajne vršila s vrlo dobrim znanjem i uspjehom. U radu je bila uvijek savjesna $i$ vrlo uredna, postupak s bolesnicima odličan. Istu potvrdu 
izdaje i 30. svibnja 1944. godine, kao potrebnu dokumentaciju za priznavanje specijalističkog zvanja kirurga. Takvu potvrdu izdaje i upravitelj Državne bolnice u Bjelovaru, prim. dr. Franjo pl. Fanton, posebice o njezinu kirurško-ginekološkom radu za vrijeme prim. dr. Nikole Karlića do r940. godine. ${ }^{17}$ Dr. Bosner ispunila je 9. rujna I942. upitni prilog molbi za namještenje u $\mathrm{NDH}$ u kojem uz generalije obiteljskoga podrijetla ispunjava podatke da nije bila članicom nikakve političke ili društvene organizacije te traži promaknuće sa svojim potpisom i potpisom bjelovarskoga tabornika Matije Navojca. ${ }^{18}$

Na odlasku iz Bjelovara dr. Ljubica Bosner traži Ministarstvo zdravstva NDH da ju premjesti na službu u Babičku školu u Zagreb (Petrova klinika) jer je, kako navodi, radila u državnoj službi I2 godina, od čega 8 mjeseci na ortopedskom odjelu u Velikoj Gorici, kirurškim odjelima u bolnicama u Ogulinu i Bjelovaru i stekla iskustvo iz ginekoloških operacija i u porodništvu, pa za tu medicinsku granu osjeća posebnu sklonost $i$ željela bi se u njoj specijalizirati. ${ }^{19}$ No njezina molba za specijalizaciju iz ginekologije i porodništva očito nije prihvaćena jer je dobila postavljenje na Kirurškom odjelu u novootvorenoj Zakladnoj bolnici na Rebru od 22. rujna 1942. ${ }^{20}$

Nedugo nakon zaposlenja na Rebru, 24. studenoga 1942. Državna bolnica u Petrinji tražila je hitnu zamjenu za akutno bolesnog predstojnika Kirurškog odjela dr. Peterneka (od gnojnoga iritisa) pa glavni ravnatelj za zdravstvo dr. Stipčić naređuje da se dr. Ljubica Bosner, asistentica VIII. činovnog razreda na radu u Zakladnoj bolnici Rebro, pošalje na zamjeničku službu u bolnicu u Petrinju dokle god služba zahtijeva te da joj pripadaju putni troškovi i dnevnice službovanja. Tako se 2. prosinca 1942. dr. Bosner isplaćuju dnevnice od 3740 kuna za zamjeničko službovanje u bolnici u Petrinji. Dana 6. svibnja 1943. dr. Šime Cvitanović ponovno traži putni nalog i isplatu za dr. Bosner za službu u Petrinji, a 5. svibnja 1943. se konačno razrješuje obveza u bolnici u Petrinji. ${ }^{21} \mathrm{O}$ predratnim, a posebice o ratnomedicinskim zbivanjima u Petrinji i Ogulinu, ne postoje nikakvi podatci niti u značajnom djelu Akademije medicinskih znanosti glavnoga urednika prof. Ive Mlinarića

17 Hrvatski državni arhiv Zagreb, Zbirka 890. Zbirka personalnih spisa državnih službenika Zemaljske vlade, Pokrajinske uprave, oblasnih uprava, Savske banovine, Banovine Hrvatske i ministarstava Nezavisne Države Hrvatske.

18 Ibid.

19 Ibid.

20 Hrvatski državni arhiv Zagreb, Fond 226. Ministarstvo zdravstva i udružbe Nezavisne Države Hrvatske (MZU NDH), Odjel za zdravstvo (OzZ).

21 Hrvatski državni arhiv Zagreb, Zbirka 890. Zbirka personalnih spisa državnih službenika Zemaljske vlade, Pokrajinske uprave, oblasnih uprava, Savske banovine, Banovine Hrvatske i ministarstava Nezavisne Države Hrvatske. 
o povijesti kirurških struka u Hrvatskoj, ${ }^{22}$ pa je zasigurno i djelovanje dr. Bosner u obje bolnice, što je istraženo i publicirano, prilog povijesti medicine i ratne kirurgije u tim mjestima.

Prema dokumentima, dr. Ljubica Bosner je u stalnom namještenju na Kirurškom odjelu Zakladne bolnice Rebro u Zagrebu bila od 22. rujna I942. do Io. listopada I945. godine. Budući do nema sačuvanih operacijskih protokola iz toga vremena, nisu razvidni operacijski zahvati koje su izvodili kirurzi Kirurškoga odjela, no postoje matične knjige prijma u bolnicu, pa tako i na Kirurški odjel u kojem se bilježe brojne ratne ozljede i mirnodopska kirurgija od pedijatrijske do gerijatrijske, poput one u bjelovarskoj bolnici. Dakle, prema prijamnim dijagnozama, u Kirurškom odjelu nove Zakladne bolnice na Rebru izvodili su se svi operacijski kirurški zahvati toga vremena, posebice što su na tom odjelu radili iznimno iskusni kirurzi poput predstojnika odjela prim. dr. Marija Duića, prim. dr. Šime Cvitanovića i dr. Ljubice Bosner, uz ostale odjelne liječnike. Budući da je bolnica imala ustrojene odjele za okulistiku, otorinolaringologiju, ortopediju i ginekologiju s rodilištem, navedeni kirurzi, premda izučeni posebice u ginekologiji i porodništvu, nisu obavljali operacijske zahvate iz tih specijalističkih područja jer su ti odjeli imali svoje namještene specijaliste i sekundarne liječnike. . $3,24,25^{2}$

Od I. siječnja i944. određuje se dr. Bosner posebni dodatak na plaću u iznosu od 3500 kuna mjesečno. Dana i2. veljače i944. Odredbom glavnog zapovjedništva za zdravstvo NDH dr. Bosner određena je za zamjeničko službovanje umjesto šefa kirurgije dr. Steve Nikolića u Gradsku bolnicu u Varaždinu, pa dr. Šime Cvitanović, ravnatelj bolnice Rebro, 3. svibnja I944. ponovno traži putne troškove za njezinu obavljenu dvomjesečnu službu u Varaždinu. ${ }^{26,27}$

22 Mlinarić, Ivo et al. (2002). Povijest kirurških struka u Hrvatskoj, Zagreb; Akademija medicinskih znanosti Hrvatske.

23 Hrvatski državni arhiv Zagreb, Zbirka 890. Zbirka personalnih spisa državnih službenika Zemaljske vlade, Pokrajinske uprave, oblasnih uprava, Savske banovine, Banovine Hrvatske i ministarstava Nezavisne Države Hrvatske.

24 Hrvatski državni arhiv Zagreb, Fond 226. Ministarstvo zdravstva i udružbe Nezavisne Države Hrvatske (MZU NDH), Odjel za zdravstvo (OzZ).

25 Klinički bolnički centar Zagreb, Pismohrana (KBCZ-P). Matične knjige bolesnika 1942.-1945.

26 Hrvatski državni arhiv Zagreb, Zbirka 890. Zbirka personalnih spisa državnih službenika Zemaljske vlade, Pokrajinske uprave, oblasnih uprava, Savske banovine, Banovine Hrvatske i ministarstava Nezavisne Države Hrvatske.

27 Hrvatski državni arhiv Zagreb, Fond 226. Ministarstvo zdravstva i udružbe Nezavisne Države Hrvatske (MZU NDH), Odjel za zdravstvo (OzZ). 
Dana 7. lipnja 1944. predstojnik Kirurškog odjela Zakladne bolnice Rebro u Zagreb prim. dr. Mario Duić daje Uredovnu potvrdu o radu dr. Ljubice Bosner: $^{28}$

...Kroz čitavo to vrieme naročito se istakla svojim marom, radinošću i sposobnošću u vršenju povjerenoj joj dužnosti. Također naročito ističem način saobračaja, susretlivosti i ljubavi prema bolestnicima. Na odjelu je obavljala sav povjereni joj posao sa osobitom spretnošću i uspjehom. Koliko rad na odjelu, toliko u operacionim dvoranama mora se pohvaliti radi spretnosti i vrlo dobrih uspjeha. Radila je na području čitave kirurgije, koliko kliničkih pretraga, toliko na području operativne kirurgije. Samostalno je izvadjala i vrlo teške operacije iz raznih područja s odličnim uspjehom. Sve u svemu može se pohvaliti čitav njezin rad i njezina spremnost, kao $i$ uspjesi u operativnim zahvatima.

Prim. dr. Mario Duić (rgor. - 196r.), kirurg, završio je medicinu u Grazu, radio na Kirurškom odjelu u Osijeku, koji je vodio početkom Drugoga svjetskog rata do namještenja za predstojnika novoustrojenog Kirurškoga odjela novootvorene Zakladne bolnice Rebro, a nakon rata radi u Puli kao primarni liječnik Kirurškoga odjela. Bio je predsjednik Hrvatskoga liječničkoga zbora podružnice Pula 1948. - 1949. i zaslužni liječnik za razvoj kirurgije u poratnoj Istri. $^{29}$

Dana 9. lipnja 1944. dr. Bosner podnijela je zahtjev za priznavanje naziva specijalista i obavljanje specijalističke prakse iz kirurgije, uz podnošenje mišljenja šefova Odjela kirurgije prim. dr. Josipa Jagodića iz Bjelovara i prim. dr. Marija Duića iz Zakladne bolnice na Rebru te potvrdu Hrvatske liječničke komore Nezavisne Države Hrvatske o liječničkome stažu, budući je na tom poslu provela devet godina službe. Dana 5. kolovoza 1944. Glavni ravnatelj za zdravstvo NDH odobrava joj naziv specijalistice kirurginje i pravo obavljanja specijalističke prakse iz kirurgije. ${ }^{30,31}$

Do kraja Drugoga svjetskoga rata radila je na Kirurškom odjelu Zakladne bolnice Rebro, a 8. svibnja 1945. imenovana je za šeficu Odjela kirurgije mekih česti iste bolnice. Dana 24. studenoga 1945. dr. Ljubica Bosner javlja se

28 Hrvatski državni arhiv Zagreb, Zbirka 890. Zbirka personalnih spisa državnih službenika Zemaljske vlade, Pokrajinske uprave, oblasnih uprava, Savske banovine, Banovine Hrvatske i ministarstava Nezavisne Države Hrvatske.

29 Mlinarić, Ivo et al. (2002).

30 Hrvatski državni arhiv Zagreb, Zbirka 890. Zbirka personalnih spisa državnih službenika Zemaljske vlade, Pokrajinske uprave, oblasnih uprava, Savske banovine, Banovine Hrvatske i ministarstava Nezavisne Države Hrvatske.

31 Hrvatski državni arhiv Zagreb, Fond 226. Ministarstvo zdravstva i udružbe Nezavisne Države Hrvatske (MZU NDH), Odjel za zdravstvo (OzZ). 
Ministarstvu narodnoga zdravlja Federalne Republike Hrvatske radi dobivanja propusnice zbog odlaska na novu dužnost koju treba preuzeti 24. studenoga 1945., a nakon razrješenja dužnosti u bolnici Rebro od Io. listopada 1945. godine. ${ }^{32}$ Otad radi kao upraviteljica bolnice u Malom Lošinju, koja je bila pod upravom Oblasnog narodnog odbora (NO) za Istru, do 29. rujna 1946. od kada je zaposlenica na Kirurškom odjelu bolnice u Rijeci gdje će dočekati mirovinu. ${ }^{33-35}$

U njezino profesionalno vrijeme kirurgijom se bavilo vrlo malo žena liječnica - dr. Emilija Lazić (Ogulin), dr. Božidara Herkov (Ogulin, Duga Resa) i dr. Mirjana Hafner Iveković (Nova Gradiška), ali do mirovine, cijeli profesionalni staž, kirurgijom se bavila samo dr. Ljubica Bosner kao specijalistica kirurginja, dok su druge liječnice poslije radile u nekirurškim strukama.

Uz postojeće radove, ovaj će prilog zasigurno biti dopuna biografiji prim. dr. Ljubice Bosner i poznavanju zbivanja u hrvatskom zdravstvu prije, za vrijeme i neposredno nakon Drugoga svjetskoga rata.

\section{Bibliografija}

IZVORI

1. Državni arhiv Zagreb, Fond 1282. Opća javna županijska bolnica Velika Gorica.

2. Hrvatski državni arhiv Zagreb, Zbirka 890. Zbirka personalnih spisa državnih službenika Zemaljske vlade, Pokrajinske uprave, oblasnih uprava, Savske banovine, Banovine Hrvatske i ministarstava Nezavisne Države Hrvatske.

3. Hrvatski državni arhiv Zagreb, Fond 226. Ministarstvo zdravstva i udružbe Nezavisne Države Hrvatske (MZU NDH), Odjel za zdravstvo (OzZ).

4. Klinički bolnički centar Zagreb, Pismohrana (KBCZ-P). Matične knjige bolesnika 1942.-1945.

5. Škarpa, Antun. Prim. dr. Ljubica Bosner. Pismo. Privatno vlasništvo.

32 Hrvatski državni arhiv Zagreb, Zbirka 890. Zbirka personalnih spisa državnih službenika Zemaljske vlade, Pokrajinske uprave, oblasnih uprava, Savske banovine, Banovine Hrvatske i ministarstava Nezavisne Države Hrvatske.

33 Ibid.

34 Habek, Dubravko (2013), 237.

35 Škarpa, Antun. Prim. dr. Ljubica Bosner. Pismo. Privatno vlasništvo. 


\section{LITERATURA}

1. Habek, Dubravko (2009), Kirurška služba u Bjelovaru tijekom II. svjetskog rata, Liječ Vjesn, 131, 93.

2. Habek, Dubravko (2009), Prve liječnice u Bjelovaru: porodničarka i kirurginje, Liječ Vjesn 131, 155.

3. Habek, Dubravko (2013), Prim. dr. Ljubica Bosner, kirurginja, porodničarka i ginekologinja, Acta Med Hist Adriat, 11(2), 237.

4. Hajduković, Nikola (1995). Sto godina kirurgije u Osijeku - kronologija 1895.-1995. Ravnateljstvo Kliničke bolnice Osijek.

5. Mlinarić, Ivo et al. (2002). Povijest kirurških struka u Hrvatskoj, Zagreb; Akademija medicinskih znanosti Hrvatske.

\section{SUMMARY}

Previously were published well-known data on Rijeka physician, Dr Ljubica Bosner, about her work in the Ogulin, Bjelovar, Petrinja and Rijeka hospitals during her excellent surgical and gynaecological and obstetric practice. The new and now accessible archives of personal and professional items complete incomplete and unknown biographical information. After her internship, Dr Bosner worked at a public county hospital in Velika Gorica as a secondary doctor at a well-known orthopaedic ward of that hospital. Circumstances of going to the Ogulin hospital with an oath to the reigning King Peter II for fidelity, then her professional activity as a surgeon at the newly opened Foundation Hospital Rebro Zagreb, with occasional departures to the position of director of the hospital and surgeon in Petrinja and Varaždin, and after the war to new positions at the Regional People's Board in Istria, are of particular social and historical interest. Recommendations from her bosses have been found to recognise the profession of surgeon specialist that particularly emphasise her skills, clinical judgment, and performance of major surgical procedures, especially during the war. Her life and medical career went through periods of great crisis between the two world wars (during the Kingdom of Serbs, Croats and Slovenes), then World War II (during the Independent State of Croatia), and after the war and the Republic of Yugoslavia in which she acted as a surgeon. The above data in the biography of Dr Ljubica Bosner are completed by previously unknown and unpublished photographs from her personal and professional surgical life.

Keywords: history of medicine, history of surgery, Ljubica Bosner, Croatia 